\title{
Characterization of groundwater resources degradation at Santiago Island (Cabo Verde) ascribed to isotopic and geochemical signatures
}

\author{
P. M. Carreira ${ }^{1}$, J. M. Marques ${ }^{2}$, A. Pina ${ }^{3}$, A. Mota Gomes ${ }^{3}$, \\ D. Nunes ${ }^{1} \&$ F. Monteiro Santos ${ }^{4}$ \\ ${ }^{1}$ Instituto Tecnológico e Nuclear, Departamento de Química, \\ Sacavém, Portugal \\ ${ }^{2}$ Instituto Superior Técnico, Lisboa, Portugal \\ ${ }^{3}$ Instituto Superior de Educação, Praia, Santiago, Cabo Verde \\ ${ }^{4}$ Universidade de Lisboa, Centro de Geofísica, Lisboa, Portugal
}

\begin{abstract}
Overexploitation of coastal aquifers and pollution are among the main problems related to groundwater resources assessment and management in Santiago Island (Cabo Verde). Brackish groundwater for agriculture and human supply (e.g. Praia Baixo, Montenegro, and Charco) are being provided to populations as the only type of available water. Isotopic techniques combined with geochemical signatures provided information about salinization mechanisms (e.g. seawater intrusion, salt dissolution, and marine aerosols) of the groundwater systems, at Santiago Island. The isotopic composition of groundwater samples range from -4.98 to $-2.61 \%$ in $\delta^{18} \mathrm{O}$ and from -44.6 to $-14.9 \%$ in $\delta^{2} \mathrm{H}$, with a mean isotope content of $-3.88 \pm 0.53 \%$ in $\delta^{18} \mathrm{O}$ and $-25.9 \pm 5.4 \%$ in $\delta^{2} \mathrm{H} v s \mathrm{~V}$-SMOW $(\mathrm{n}=$ 115). Two groundwater groups were recognized based on the $\delta^{18} \mathrm{O}$ and $\delta^{2} \mathrm{H}$ isotopic composition and different geochemical evolution trends were identified: (i) mixture with seawater (the influence of marine aerosol cannot be excluded) and (ii) same isotopic "history" but different geochemical evolution, depending on weathering rates and rock permeability.
\end{abstract}

Keywords: groundwater degradation, geochemistry, stable isotopes, Santiago Island - Cabo Verde. 


\section{Introduction}

Groundwater resources in arid and semi-arid regions play a vital role on the socio-economic development. Often, surface waters are either seasonal or nonexistent and groundwater becomes the recurring source of water supply. Besides, due to water scarcity problems, saltwater intrusion, with the consequent damages of coastal aquifers, is one of the natural hazards that can have enormous consequences in agriculture based societies and linked urban development.

As an alternative to a just hydrodynamic approach, geochemical and isotopic investigations of the aquifer systems have often proven to be quite successful in determining groundwater recharge, flow paths and renewal times in arid and semi-arid regions [1-3]. The advantage of such approach is that the chemical and isotopic data can provide integrated information of all water that enters the system, thereby largely eliminating local differences and short-term variability observed in the hydrodynamic data.

Overexploitation of coastal aquifers and pollution are among the main problems related to groundwater resources assessment and management in Santiago Island (Cabo Verde archipelago). As a consequence to the scarce precipitation and difficulties in the water administration, the fresh water management in Santiago Island is in a fragile balance with the seawater at coastal areas. On land, due to groundwater exploitation in the valleys near the coast, a careful monitoring of the fresh-salt water interface is being carried out in order to avoid saltwater pumping. The impact of such knowledge is vital since most part of population at Santiago Island lives by the ocean and has agriculture as the main activity. Flash floods immediately after the rainfall events and erosion of the landscape are the common rule. Surface waters are either seasonal or non-existent, and groundwater becomes the recurrent source of water supply.

Under the scope of the R\&D Project "Hydroarid - Evaluation of the Hydrogeological Potential and Sea Water Intrusion Monitoring in Semi-Arid Zones using a Multi-technique Approach: Application to the Santiago and Maio Islands (Cabo Verde)" three fieldwork campaigns were carried out at Santiago Island, with the main purpose of: (i) recognize the origin and mechanisms of groundwater recharge, (ii) investigate the existence of salt water intrusion problems and (iii) estimate the apparent groundwater "age", based on the isotopic $\left({ }^{3} \mathrm{H}\right.$ and $\left.{ }^{14} \mathrm{C}\right)$ signatures.

\section{Study area}

Located in the Southeastern part of Cabo Verde archipelago, Santiago Island presents climatological and hydrogeological features typical of sahelian regions were the seasonal changes are related to the Inter Tropical Front (ITF) [4]. The rain distribution is irregular, varying between 190 to $320 \mathrm{~mm} /$ year at low levels near the coast and at the highest mountains, respectively. The wet period is distributed from August to November [5, 6]. All over the year the temperature values show a small fluctuation, around $6{ }^{\circ} \mathrm{C}$ between mean winter season (minimum value around $22{ }^{\circ} \mathrm{C}$ at February) and the mean summer season 
(maximum value about $27^{\circ} \mathrm{C}$ at September). The wind is rather constant during all over the year, with highest intensity between January to May, with a main direction N-NE. The regular winds that cross the Island play an important role in the diffusion and transport of marine aerosols, one possible source to the income of salts to the groundwater systems.

All the islands from Cabo Verde Archipelago have a volcanic origin. The Santiago Island is constituted by a vulcano-stratigraphic sequence, as first reported by Serralheiro [7], and later improved by Matos Alves et al. [8], fig. 1.

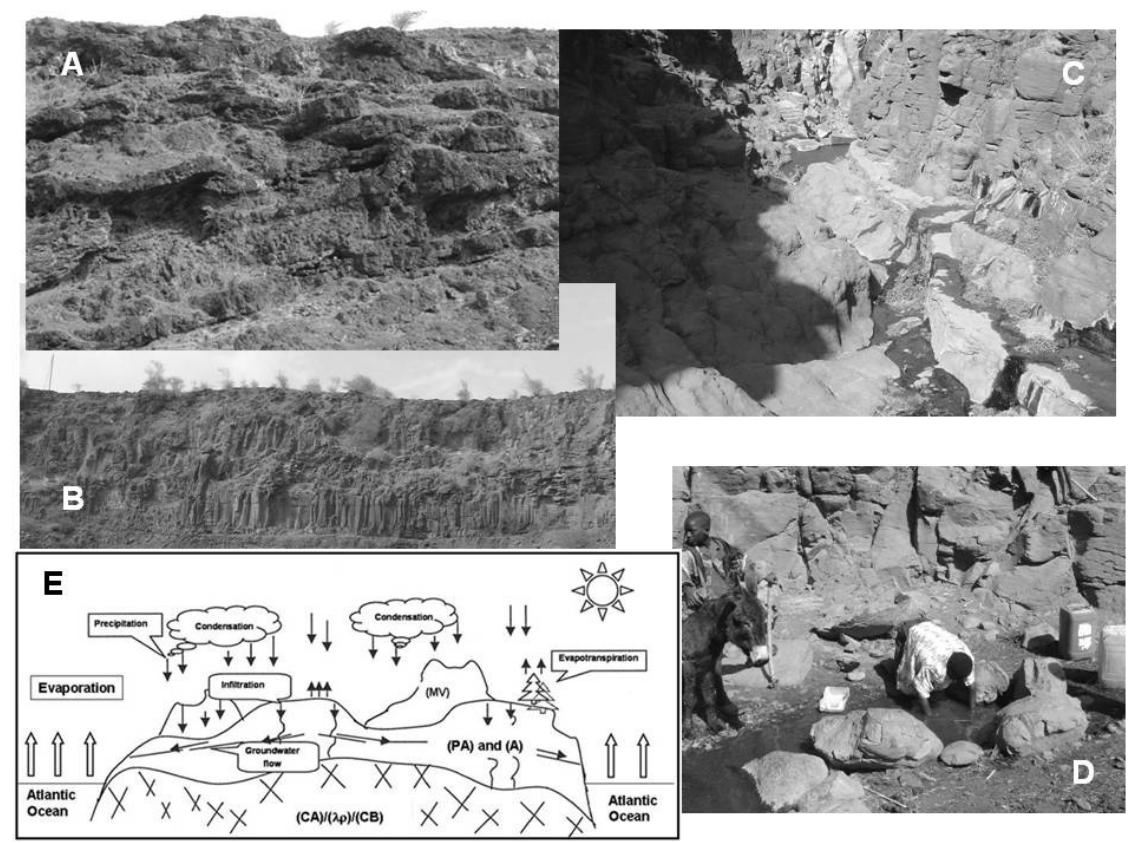

Figure 1: Santiago Island geological environment. (A) PA formation, subaerial facies (B) prismatic basalt; (C and D) geological contact between the prismatic fissured basalt and the compact basalt (impermeable) where the Águas Podres spring issue and (E) schematic conceptual hydrogeological model of Santiago Island (adapted from [5]).

The main geological units with hydrogeological interest are the following: (i) the Eruptive complex of Pico da Antonia $(P A)$ and Assomada $(A)$; (ii) the Monte das Vacas formation $(M V)$ and (iii) the recent sedimentary Quaternary formations (a). The most important reservoir of fresh water is the PA formation presenting terrestrial and submarine facies (pillow-lavas). The storage coefficient of the PA and A formations is relatively high; their permeability avoids a rapid drainage of the scarce water supply with high feed rate. These units cover an impermeable formation known as the Base Unit $\left(\mathrm{CA} / \lambda_{\mathrm{Q}} / \mathrm{CB}\right)$ composed by 
Ancient Internal Eruptive Complex (AIEC). The Flamengo and the Conglomeratic-Brechoide formations, two components of the AIEC, are characterized by presenting a practically generalized alteration level, high rate of compactness and low permeability.

\section{Results and discussion}

\subsection{Hydrogeochemical setting}

Three groundwater-sampling campaigns were performed at Santiago Island (November 2005, February and November 2006). The groundwater samples were collected from boreholes and springs for isotopic analyses $\left(\delta^{2} \mathrm{H}, \delta^{18} \mathrm{O}\right.$ and $\left.{ }^{3} \mathrm{H}\right)$. Electrical conductivity $(\mu \mathrm{S} / \mathrm{cm}), \mathrm{pH}$ and temperature $\left({ }^{\circ} \mathrm{C}\right)$ were measured in situ. No groundwater samples have been collected for chemical analyses, due to the fact that a large chemical data were available in the framework of previous campaigns carried out at Santiago Island by part of the team members of the present research group. Electrical conductivity (EC) was measured in all sampling sites. The values obtained range between 130 to $9400 \mu \mathrm{S} / \mathrm{cm}$. The groundwater samples collected in the central part of Santiago Island, such as Pico da Antónia or Serra Malagueta, belong to the $\mathrm{Na}-\mathrm{HCO}_{3}$ type, pointing to the influence of the geological matrix (volcanic terrains). On the other hand, the highest salt content is found in the valleys, areas of intense agriculture practices (sugar cane, banana and papaya fields), indicating a salt increase associated with excessive pumping of the aquifer systems, fig 2 .
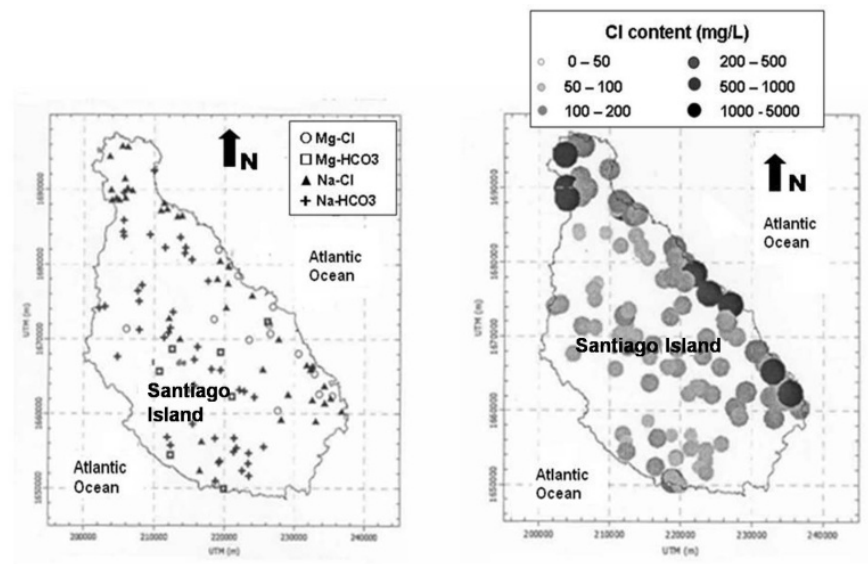

Figure 2: Groundwater geochemical facies distribution and $\mathrm{Cl}$ content distribution at Santiago Island (adapted from [5]).

Most of the groundwater samples presenting high sodium and chloride contents are ascribed to the valleys situated at the coastal areas, indicating seawater intrusion as the main mechanism responsible for the groundwater 
salinity. Nevertheless, the influence of marine aerosol cannot also be excluded as one of the salinity sources.

Natural salinity boundaries exist in aquifers due to geological factors controlling the maximum depth of circulation, as well the interface between marine and fresh water. Climatic factors strongly control salinity, so that continuous low rate of recharge in arid areas, lead to a widespread salinity of groundwaters. Human factors also exacerbate salinity directly by pollution or indirectly by agricultural activities and extreme pumping leading to the incursion of saline groundwater into freshwater aquifers. These situations can be well observed at Santiago Island.

In order to observe the spatial variations of the geochemical data at Santiago Island some geochemical parameters were plotted versus the total ions (TDS) of the groundwater samples. No correlation was found between the geochemical evolution and i) the particular geological layer or ii) the type of sampling point (spring or borehole). However, trends with geochemical significance were established between the total ions and $\mathrm{Mg}, \mathrm{SO}_{4}, \mathrm{Ca}, \mathrm{HCO}_{3}, \mathrm{Na}$ and $\mathrm{Cl}$ contents, fig. 3 .
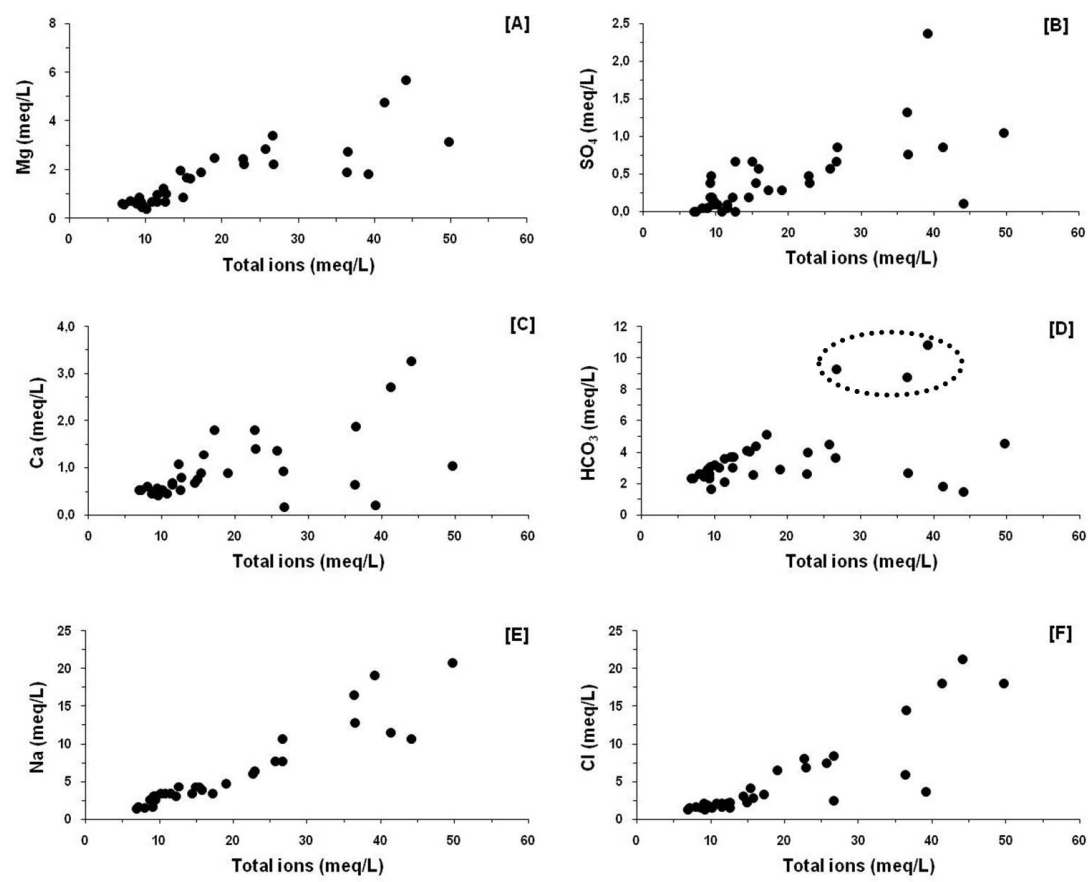

Figure 3: Major ion composition diagrams of the groundwater samples collected at Santiago Island, exploiting different aquifer systems, versus total ions (meq/L).

An increase of the ion content with the raise of the total ion amount (TIA) is more or less clearly observed in all diagrams. In addition, when the TIA reach 
values around $30 \mathrm{meq} / \mathrm{L}$, the ion content seems to become stationary or in some cases even decreases. This behavior probably indicates that the groundwater samples have reach saturation values with respect to $\mathrm{Ca}$ and $\mathrm{Mg}$ carbonates and gypsum. The low content in $\mathrm{Na}$ and $\mathrm{Cl}$ is followed by a small range in the TIA values and increase as TIA rises, indicating that the higher salinization of the groundwaters should be related to $\mathrm{NaCl}$ dissolution.

It is important to point out that at Santiago Island the land affected by seawater intrusion or the influence of marine aerosol appears to be moving forward, as supported by the recent increase in the groundwater electrical conductivity data, towards sampling sites located rather far from the sea. The high salt content within the groundwater systems appears to be ascribed to agricultural zones (in the valley areas) located in the coast surroundings. The salt increase measured in the groundwater is consistent with intense exploitation of the groundwater resources and the scarcity of precipitation. The salt increase leads to a potential opening for soil salinization and alkalinisation, with the inherent soil deterioration and loss of productivity. In most cases the amount of water supplied for irrigation exceed the drainage capacity of the soil.

\subsection{Environmental isotope approach}

Based simply on the geochemical signatures of the groundwaters it is difficult to give a direct answer regarding the origin of the groundwater salinization. The major challenge of this study is to distinguish saline groundwaters of different origins, and for this purpose, both geochemical and isotopic techniques are required. Over the past 40 years isotope methods have proved to be of unique value in understanding the origins of salinity as well as the process of salinization in groundwaters. Coupled measurements of chloride and sodium, when combined with the stable isotope $\left(\delta^{2} \mathrm{H}\right.$ and $\left.\delta^{18} \mathrm{O}\right)$ content of groundwaters have provided a powerful technique in numerous studies of the evolution of groundwater salinity as well as recharge/discharge relationships $[1,10]$.

Close to 120 groundwater samples for comprehensive environmental isotopic $\left({ }^{2} \mathrm{H},{ }^{18} \mathrm{O}\right.$ and $\left.{ }^{3} \mathrm{H}\right)$ analysis were taken from boreholes and springs during three field work campaigns at Santiago Island. The isotopic data was semi-statistically treated, since no correlation was found between the geological formations and the groundwater's physico-chemical signatures. The isotopic composition of the groundwater samples collect at Santiago Island range from -4.98 to $-2.61 \%$ in $\delta^{18} \mathrm{O}$ and from -44.6 to $-14.9 \%$ in $\delta^{2} \mathrm{H}$, with a mean isotope content of $-3.88 \pm$ $0.53 \%$ in $\delta^{18} \mathrm{O}$ and $-25.9 \pm 5.4 \%$ in $\delta^{2} \mathrm{H} v s \mathrm{~V}-\mathrm{SMOW}$, fig. 4 .

The isotopic content obtained is close to the average isotopic composition over the Island as discussed by Akiti [9], suggesting that the infiltrated meteoric waters were not subjected to previous evaporation. Two groups of groundwater samples can be identified in the diagram $\delta^{18} \mathrm{O} v s$. $\delta^{2} \mathrm{H}$, fig.4. One group encloses groundwater samples collected in the eastern part of Santiago Island, in most cases located near the coastline. The other group is ascribed to high-altitude sampling sites, i.e. most of the sampled points are located in the middle of the Island. Based on this pattern, we have tried to identify a possible relationship 
between the altitude of the sampling sites and the isotopic composition, but no strong correlation was found.

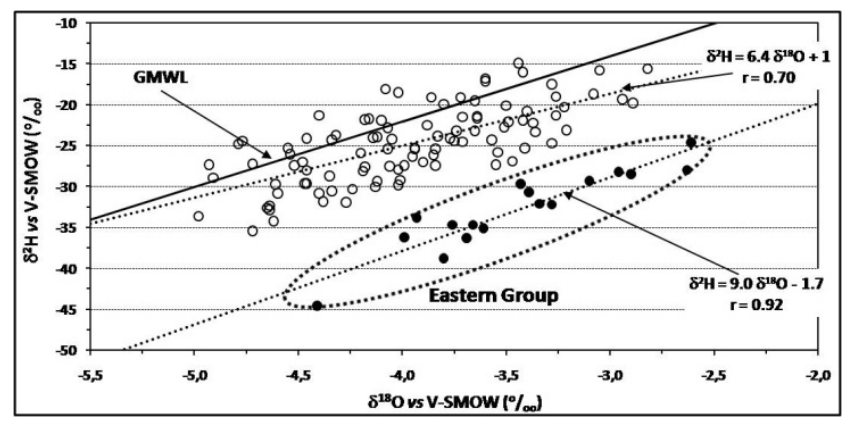

Figure 4: $\quad \delta^{2} \mathrm{H}$ versus $\delta^{18} \mathrm{O}$ for the sampled groundwaters

One possible explanation for this isotopic "distribution" (e.g. eastern group) could be ascribed to infiltration / recharge under different climatic conditions. The hypothesis of the existence of a palaeoclimatic signature within these two groundwater groups should be formulated. The present day representative values in oxygen-18 and in deuterium observed in precipitation may be used as sensitive indicators of climatic changes and complexity in past temperature, precipitation patterns and air mass circulation. Past rainfall storage as palaeogroundwater provide evidence of former climatic conditions [10]. Climatic changes are expressed primarily as (i) isotopic depletion relative to modern groundwaters with reference to the meteoric water line (north and central Europe), (ii) change in the deuterium excess, symptomatic of changes in humidity in the air masses as they detaches from its primary oceanic source moving over arid zones and (iii) local condensation and evaporation effects within clouds or in falling rainwater.

Furthermore, the combined use of chloride and stable isotopes $\left(\delta^{18} \mathrm{O}\right.$ and $\left.\delta^{2} \mathrm{H}\right)$ of groundwater provide a powerful technique for studying past rainfall and evaporation cycles in groundwaters. According to Edmunds [10], the large freshwater reserves in some basins of modern arid zones are therefore a priori indicators of wetter climates. Besides, in shallow aquifers higher salinity is mainly a legacy of the onset of more arid conditions during the past 4000 years.

In order to try to identify climate signatures within the sampled groundwaters and characterize the possible salinization scenarios, the isotopic composition was plotted as a function of the chloride content, fig. 5. In the $\delta^{18} \mathrm{O} v s \mathrm{Cl}$ plot in fig $5 \mathrm{~A}$, the samples fall within a fan-shaped field whose boundary lines allow the evaluation of the isotopic range of a meteoric recharge of the aquifer system, having $\delta^{18} \mathrm{O}$ values in the range of -5.0 to $-4.0 \%$. The $\mathrm{Cl}$ enriched waters, are characterized by a more enriched stable isotopic content, approximating the probable seawater mixing trend line rather well. It should be stated that this trend line is more detectable within the eastern group of groundwaters. Besides, this mixing pattern is also evident when the $\delta^{18} \mathrm{O}$ values are plotted as a function of 
the electrical conductivity (EC). The enrichment in heavy isotopes is followed by an increase in the $\mathrm{EC}$ values, fig. $5 \mathrm{~B}$. In the diagram of fig. $5 \mathrm{~B}$, the trend line of the eastern group is not parallel to the $\mathrm{x}$-axis as in the diagram of fig. $5 \mathrm{~A}$.

On the other hand, in both diagrams, a number of samples reveal a significant enrichment in ${ }^{18} \mathrm{O}$, which cannot be explained due to seawater intrusion. The pattern presented by this group of groundwater samples might in part be explained by direct infiltration of irrigation waters undergoing significant evaporation during the dry periods. On the other hand, within this group of waters, the influence of marine aerosol cannot be excluded since the isotopic enrichment is also followed by an increase in the $\mathrm{Cl}$ and $\mathrm{Na}$ content.

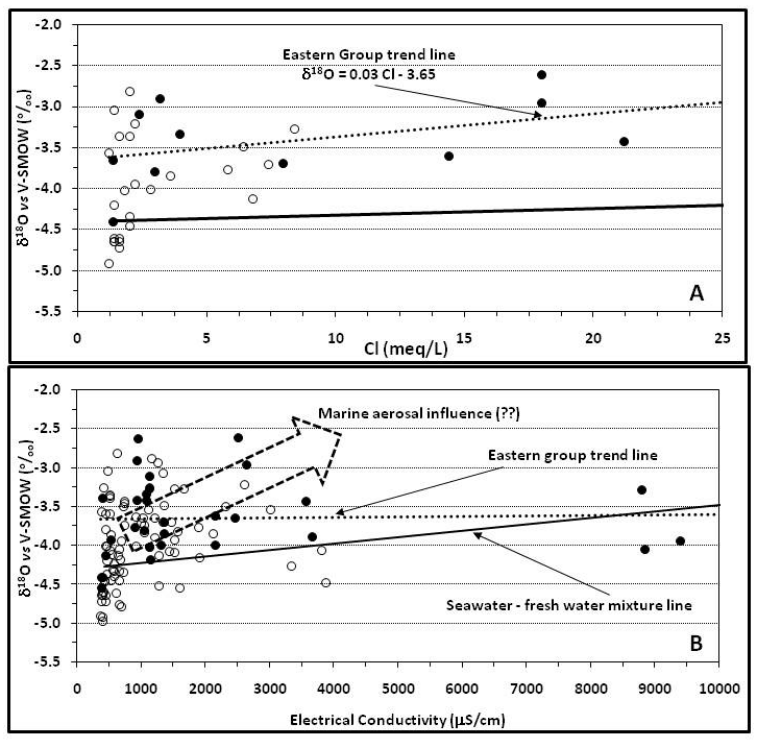

Figure 5: $\quad$ (A) $\delta^{18} \mathrm{O}$ versus $\mathrm{Cl}$ contents and (B) versus electrical conductivity of the sampled groundwaters.

Based on the $\mathrm{Mg} / \mathrm{Ca}$ ratios of the groundwater samples the hypothesis of extended water-rock interaction responsible for a change in seawater chemical composition (e.g. decrease in the $\mathrm{Mg} / \mathrm{Ca}$ ratios) was formulated. The hypothesis of the occurrence of ancient seawater trapped in the geological formations responsible for the salinization increase is still in open since the results were not conclusive, fig. 6 . The $\mathrm{Mg} / \mathrm{Ca}$ ratio of the groundwater samples is more or less constant with the increase of the total ion amount.

The tritium data reveal no useful information since most of the groundwater samples present no tritium or a low isotopic content, with values ranging from 0 \pm 0.7 TU to $3 \pm 0.7$ TU. No correlation was found between tritium concentrations either with the altitude of the sampling sites or with the electrical conductivity. Unfortunately, no long series of ${ }^{3} \mathrm{H}$ content in rainfall of the area are available for the Cabo Verde archipelago. In fact, the absence of ${ }^{3} \mathrm{H}$ and/or 
the lower content found in the groundwater samples difficult the estimation of the turnover rates of the groundwater. Nevertheless, according to the work performed by [9] in the $\mathrm{N}$ part of the island (Tarrafal) a mean residence time of 30 years was attributed. Moreover, according to that author, in the eastern part of Santiago Island, in Achada Baleia, it seems that the shallow boreholes were receiving contemporaneous recharge while the deep boreholes were receiving groundwater flowing slowly from joints and fractures.

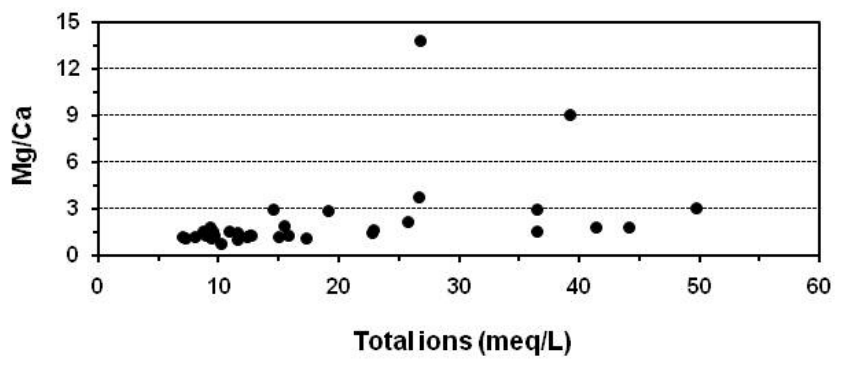

Figure 6: $\quad \mathrm{Mg} / \mathrm{Ca}$ ratios versus total ions in the sampled groundwaters.

\section{Concluding remarks and outlook}

This paper presents a case study from a semi-arid area (Santiago Island, Cabo Verde Archipelago) where the combination of geochemical and isotopic methodologies was applied to describe the origin and evolution of groundwater in coastal aquifers.

The major challenge in this study was to distinguish saline water of different origins and seawater of different generations. The results point out that, the land extent of seawater intrusion and the influence of marine aerosol appears to be moving backward, as supported by the recent increase in the groundwater electrical conductivity data towards the interior of the Island. The high salt content in groundwater systems is mostly ascribed to agricultural zones in valley areas and seaside surroundings, interconnected with intense overexploitation of the groundwater resources and the scarcity of precipitation. The isotopic pattern presented by the groundwater samples can part be explained by the fact that they have been more or less subjected to evaporation. In fact, the more positive $\delta^{18} \mathrm{O}$ groundwater values could be related to direct infiltration of irrigation waters undergoing significant evaporation, during the dry periods. On the other hand, within this group of waters, the influence of marine aerosol cannot be excluded since the isotopic enrichment is also followed by an increase in the $\mathrm{Cl}$ and $\mathrm{Na}$ content.

The effective management of water resources at Santiago Island requires the permanent evaluation of available groundwater resources through a multidisciplinary approach including further detailed isotopic, geochemical and geophysical surveys. 


\section{Acknowledgements}

This study was performed under the scope of the R\&D Project "HYDROARID"

- POCI/CTE/GEX/55399/2004, granted by the Portuguese Foundation for Science and Technology (FCT) and FEDER EU Programme.

\section{References}

[1] Edmunds, W.M. \& Walton, N.R.G., A geochemical and isotopic approach to recharge evaluation in semi-arid zones; past and present, Proc. of Advisory Group Meeting, Arid-Zone Hydrology, Investigations with Isotope Techniques. Eds. I.A.E.A., Vienna, pp. 47-68, 1980.

[2] Ojeda, C.G., Aquifer recharge estimation at Mesilla Bolson and Guaymas aquifer systems, Mexico. Proc. Research Co-ordination Meeting, Isotope based assessment of groundwater renewal in water scarce regions eds. IAEA-TECDOC-1246, Vienna, pp. 23-44, 2001.

[3] Weyhenmeyer, C.E., Groundwater evolution in an arid coastal region of the Sultanate of Oman Based on geochemical and isotopic tracers. Water-Rock Interaction. Water Science and Technology Library, 40, pp. 1-38, 2002.

[4] I.N.G.R.H. (Instituto Nacional de Gestión de Recursos Hídricos) Cooperacion Espanõla, Geo-hydrological syntesis of Cabo Verde. Instituto Nacional de Gestión de Recursos Hídricos, Open Report, 68 pp. (in Spanish), 1994.

[5] Lobo de Pina, A.F., Mota Gomes, A., Condesso de Melo, M.T., Marques da Silva, M.A., Hydrogeochemical characterization of the main aquifer units of Santiago Island, Cabo Verde. Proc. of XIV Semana de Geoquímica / VIII Congresso de Geoquímica dos Países de Língua Portuguesa (1) pp. 379 382, 2005 (in Portuguese).

[6] I.A.E.A., Atlas of isotope hydrology - Africa. I.A.E.A. Eds, Vienna, pp. 15-16, 2007

[7] Serralheiro, A., Santiago Island Geology (Cabo Verde). Universidade de Lisboa, Portugal, 278 pp (unpublished PhD Thesis - in Portuguese), 1974.

[8] Matos Alves, C.A., Macedo, J.R., Celestino Silva, L., Serralheiro, A., Peixoto Faria, A.F., Geologic, petrological and vulcanological study of Santiago Island (Cabo Verde). Revista Garcia da Orta, Série de Geologia, 3 (1-2), pp. 70-81, (in Portuguese), 1979.

[9] Akiti, T., Environmental isotope study of the groundwaters of the island of Santiago, Cape Verde. International Atomic Energy Agency, Division of Research and Laboratories, Section of Isotope Hydrology, Internal Report, Vienna, Austria. 54pp, 1979.

[10] Edmunds, W.M., Groundwater as an archive of climate and environmental change (Chapter 21). Isotopes in the water cycle. Past present and future of developing science, eds. KA Pradeep, J.R. Gat \& K.F.O. Froehlich KFO eds,. Springer, pp. 341-352, 2005. 